\title{
Severity of COPD and its relationship with IL-10
}

\author{
Bruna S.A. Silva ${ }^{\mathrm{a}, \mathrm{b}, *}$, Fábio S. Lira ${ }^{\mathrm{c}}$, Dionei Ramos ${ }^{\mathrm{d}, \mathrm{e}}$, Juliana S. Uzeloto ${ }^{\mathrm{e}}$, Fabrício Eduardo Rossi ${ }^{\mathrm{f}}$, \\ Ana Paula C.F. Freire ${ }^{\mathrm{e}}$, Rebeca N. Silva ${ }^{\mathrm{e}}$, Iara B. Trevisan ${ }^{\mathrm{e}}$, Luis Alberto Gobbo ${ }^{\mathrm{a}, \mathrm{b}, \mathrm{e}}$, \\ Ercy M.C. Ramos ${ }^{\mathrm{d}, \mathrm{e}}$
}

a Skeletal Muscle Assessment Laboratory (LABSIM), São Paulo State University (UNESP), School of Technology and Sciences, Department of Physcial Education, Presidente Prudente, SP, Brazil

${ }^{\mathrm{b}}$ Post Graduation Program in Motricity Sciences, São Paulo State University (UNESP), School of Technology and Sciences, Presidente Prudente, SP, Brazil

${ }^{\mathrm{c}}$ Exercise and Immunometabolism Research Group, Department of Physical Education, São Paulo State University (UNESP), School of Technology and Sciences, Presidente Prudente, SP, Brazil

d Department of Physical Therapy, São Paulo State University (UNESP), School of Technology and Sciences, Presidente Prudente, SP, Brazil

e Post Graduation Program in Physical Therapy, São Paulo State University (UNESP), School of Technology and Sciences, Presidente Prudente, SP, Brazil

${ }^{\mathrm{f}}$ Immunometabolism of Skeletal Muscle and Exercise Research Group, Department of Physical Education, Federal University of Piauí (UFPI), Teresina, PI, Brazil

\section{A R T I C L E I N F O}

\section{Keywords:}

COPD

Cytokine

Inflammation

Emphysema

Metabolic response

\begin{abstract}
A B S T R A C T
Background: The present study was designed to compare inflammatory and metabolic responses according to severity of airflow among patients with COPD and to verify the relationship between pulmonary function, body composition, metabolic and inflammatory profile.

Methods: Fifty-one patients with mild to very severe COPD were recruited and divided according lung function in Mild-moderate (GOLD 1-2) $n=21$; Severe (GOLD 3) $n=25$ and Very severe (GOLD 4) $n=5$. Patients were submitted to assessments of lung function (spirometry), functional exercise capacity (6-min walk test), body composition (Octopolar bioelectrical impedance), metabolic profile (glucose, triglycerides, total cholesterol, HDL-cholesterol and albumin (colorimetric assay)) and inflammatory profile (cytokines: IL-6, IL-10, TNF- $\alpha$ and IL-15 (ELISA)).

Results: We found that patients in GOLD 3 group had lower levels of IL-10, triglycerides, visceral fat area, and higher IL-6 and IL-6/IL-10 ratio when compared to GOLD 1-2 patients. Additionally, GOLD 1-2 group presented negative correlation between TNF- $\alpha$ and HDL cholesterol $(\mathrm{p}=.01)$ and positive correlation between IL-15 and FEV $_{1} /$ FVC $(\mathrm{p}=.01)$, while GOLD 3 group showed positive correlation between IL-6 and IL-10 (p < .01), IL-6 and total cholesterol $(\mathrm{p}<.01)$ and negative correlation between IL-10 and HDL-cholesterol $(\mathrm{p}=.01)$.

Conclusion: Our findings suggest that patients with severe COPD can exhibit compromised "inflammatory status", characterized by higher IL6, IL-6/IL-10 ratio and lower IL-10 concentration. Furthermore, IL-10 seems to be an interesting cytokine to be investigated in this kind of patients.
\end{abstract}

\section{Introduction}

Chronic Obstructive Pulmonary Disease (COPD) is characterized by persistent airflow limitation that is usually progressive over time. It is associated with enhanced chronic inflammatory responses in the airways and the lungs and is the fourth leading cause of death in the world, representing an important problem for public health [1-3].
Pulmonary modifications are frequently observed in patients with COPD, including changes in body composition [4,5], skeletal muscle dysfunction [6], cardiovascular disease [7], depression [8], osteoporosis [9], reduced exercise tolerance [10] and systemic inflammation [11].

Additionally, chronic systemic inflammation is associated with several risk factors and can be linked with different complications,

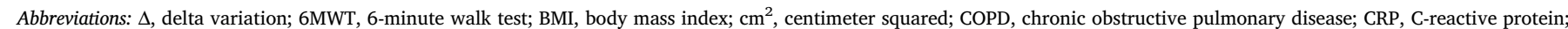

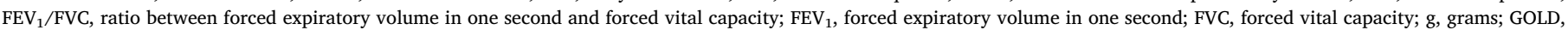

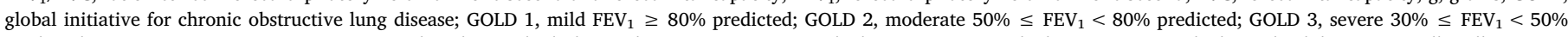

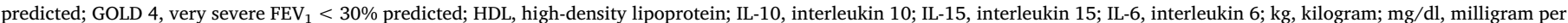
deciliter; $\mathrm{ml}$, milliliters; $\mathrm{pg} / \mathrm{ml}$, picogram per milliliters; TNF- $\alpha$, tumor necrosis factor alpha

* Corresponding author at: São Paulo State University (UNESP), School of Technology and Sciences, Presidente Prudente, Roberto Simonsen Street, 305, Educational center, 19060-900, Presidente Prudente, SP, Brazil.

E-mail address: brunaspolador@gmail.com (B.S.A. Silva). 
including atherosclerosis, cachexia, and anorexia [12]. Systemic inflammation in patients with COPD has been the focus of discussion, since it may be the cause for the development of many disorders associated with the disease. Several studies have characterized low-grade chronic inflammation by elevated serum tumor necrosis factor alpha (TNF- $\alpha$ ) and interleukin 6 (IL-6 (cytokines pro-inflammatory)) [11,13-15]. Recently, ECLIPSE study [16] showed that only $30 \%$ of patients with COPD do not exhibit increased levels of pro-inflammatory cytokines. In addition, few studies have investigated anti-inflammatory cytokines, such as interleukin 10 (IL-10) and interleukin 15 (IL-15) $[17,18]$ and the etiology of systemic inflammation in patients with COPD is still unknown.

Most physicians use a spirometric method to detect obstruction of airflow [1] and to determine the severity and progression of the disease. Studies [19-21] have demonstrated specific associations between clinical and morphological characteristics of COPD and its severity. However, it is not clear the relationship between the severity of the disease and the profile of metabolic and inflammatory markers. Therefore, the present study was designed to explore the inflammatory status of patients with COPD and to characterize them according to clinical practice. Thus, the aim of this study was to compare inflammatory and metabolic responses according to severity of airflow in patients with COPD and to verify the relationship between pulmonary function, body composition, metabolic and inflammatory profile.

\section{Material and methods}

The sample was composed of 51 clinically stable patients with mild to very severe COPD, classified according to internationally accepted criteria [1]. Patients were excluded if they were active smokers or had respiratory disorders other than COPD.

All individuals were informed beforehand of the objectives and procedures of the study and provided written consent to participate. All procedures were approved by the Research Ethics Committee (CAAE: 12492113.5.0000.5402) and followed the Resolution 466/12 of the Brazilian National Health Council. Patients were recruited by convenience sample and divided according to severity of disease to avoid potencial bias. The sample size of this study was based on the observation from a previous study that verified the relationship between IL-10 and forced expiratory volume in one second in patients with asthma-chronic obstructive pulmonary disease overlap syndrome and observed a Pearson correlation of $(r=0.58, p<$.001) [22]. Also, we used a power of 0.80 and a type I error of 0.05 according suggested by Miot et al. [23], which it estimated that we would need 21 participants per group. Considering a dropout rate of $25-40 \%$, we over-recruited the number of participants. The sample number and division are detailed in Fig. 1.

\subsection{Study design}

Patients were recruited and submitted to assessments that included: measurements of lung function (spirometry) [1,24-26], functional exercise capacity ( 6 min walk test, 6 MWT), body composition (Bioelectrical impedance), inflammatory (ELISA) and metabolic (colorimetric assay) profile. A brief description of the assessments is presented below.

\subsection{Procedures}

\subsubsection{Pulmonary function}

Spirometry was performed using a digital spirometer

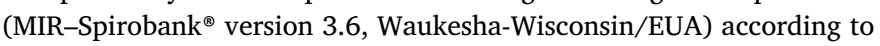
the guidelines for pulmonary function tests [24]. The interpretation of the results followed the recommendations of the American Thoracic Society and the European Respiratory Society [25] and the results were compared to data of the Brazilian population [26].

The spirometric criterion for airflow limitation was a post- bronchodilator fixed ratio of $\mathrm{FEV}_{1} / \mathrm{FVC}<0.70$. Classification of COPD severity followed the Global Initiative for Chronic Obstructive Lung Disease [1]: GOLD 1: Mild $\mathrm{FEV}_{1} \geq 80 \%$ predicted; GOLD 2: Moderate $50 \% \leq \mathrm{FEV}_{1}<80 \%$ predicted; GOLD 3: Severe $30 \% \leq \mathrm{FEV}_{1}<50 \%$ predicted; and GOLD 4: Very Severe $\mathrm{FEV}_{1}<30 \%$ predicted.

\subsubsection{Functional exercise capacity}

Functional exercise capacity was assessed using the 6 MWT, according to the guidelines of the American Thoracic Society [27]. The test was conducted in a $30 \mathrm{~m}$ track by previously trained researcher. The participants were requested to walk as fast as possible during six minutes and, if necessary, they could stop and then retake the test. Encouragement phrases were used with the purpose of keeping the same walking pace throughout the test. At the end, the walking distance was measured.

\subsubsection{Bioelectrical impedance analysis}

Bioelectrical impedance analysis was performed using the Octopolar InBody 720 Composition Analyzer (Copyright ${ }^{\circledR}$, 1996-2006, by Biospace Corporation, USA). First, the participant's age, gender and height were entered into the software. Then, the patients stood barefoot on the metal footplate and held the handles with relaxed arms. Once impedance was measured, values of fat mass $(\mathrm{kg})$, muscle mass $(\mathrm{kg})$ and visceral fat area $\left(\mathrm{cm}^{2}\right)$ of five different body sites (arms, legs, trunk and general overall set) were recorded. Anthropometric measurements were assessed by the same researcher throughout the study to minimize interpersonal errors. Patients were asked not to eat or drink two hours before the test, not to engage in moderate or vigorous exercise $24 \mathrm{~h}$ before the test, and not to consume alcohol beverages.

\subsubsection{Blood sampling analyses}

Blood samples $(15 \mathrm{ml}$ ) were collected at rest (fasting) and were immediately allocated into three different tubes: $5 \mathrm{ml}$ Vacutainer ${ }^{\circledR}$ tubes (Becton Dickinson, BD ${ }^{\circledast}$, Juiz de Fora, MG, Brazil) containing EDTA for plasma separation and one $5 \mathrm{ml}$ dry Vacutainer $^{\circledR}$ tube for serum separation. The tubes were centrifuged at $3500 \mathrm{~g}$ for $15 \mathrm{~min}$ at $4{ }^{\circ} \mathrm{C}$, and plasma and serum samples were stored at $-20^{\circ} \mathrm{C}$ until analysis. The cytokines: IL-6 (range 0.30-2.30 Log-pg/ml), IL-10 (range $0.30-2.48$ Log- pg/ml), TNF- $\alpha$ (range $0.60-2.70$ Log- pg/ml), and IL-15 (range $1.30-3.40$ Log- $\mathrm{pg} / \mathrm{ml}$ ) were analyzed using human ELISA Ready-Set-Go kits (eBioscience ${ }^{\circledR}$ Vienna, Austria). Glucose (mg/dl), triglycerides (mg/dl), total cholesterol (mg/dl) and high-density lipoprotein (HDL) cholesterol (mg/dl) were assessed using commercial kits (Labtest $^{\circledast}$, São Paulo, Brazil). Albumin measurement was analyzed by color change of Coomassie brilliant blue G-250 dye [28].

\subsection{Statistical analysis}

A statistical package (SPSS version 22.0, SPSS ${ }^{\circledR}$ Inc., USA) was used for data analysis. Normality of the data was assessed using the Kolmogorov-Smirnov test and results were described as mean \pm standard deviation or as median (interquartile range $25-75 \%$ ), according to data distribution. Categorical variables were analyzed using the chi-square test (For medicine intake GOLD groups were categorized into: GOLD $1-2=1$ and GOLD $3=2$, and drugs used: $0-1$ drugs $=$ category 1 ; 2-4 drugs $=2$; and over 5 drugs $=3$ ). The comparison between the groups GOLD 1-2 and GOLD 3 was performed using Student $t$ test for parametric distributions or the Mann Whitney test for nonparametric distributions. For biochemical variables (cytokines) was performed $t$-test on log base scale. To determine the cut-off value for IL-10 concentration, receiver-operating characteristic (ROC) curves were constructed using percentile 50 and the area under the curves (AUC) determined. The relationship between variables was analyzed using Pearson's correlation coefficient $(r)$ and the level of significance was set at $\mathrm{p}<.05$. 


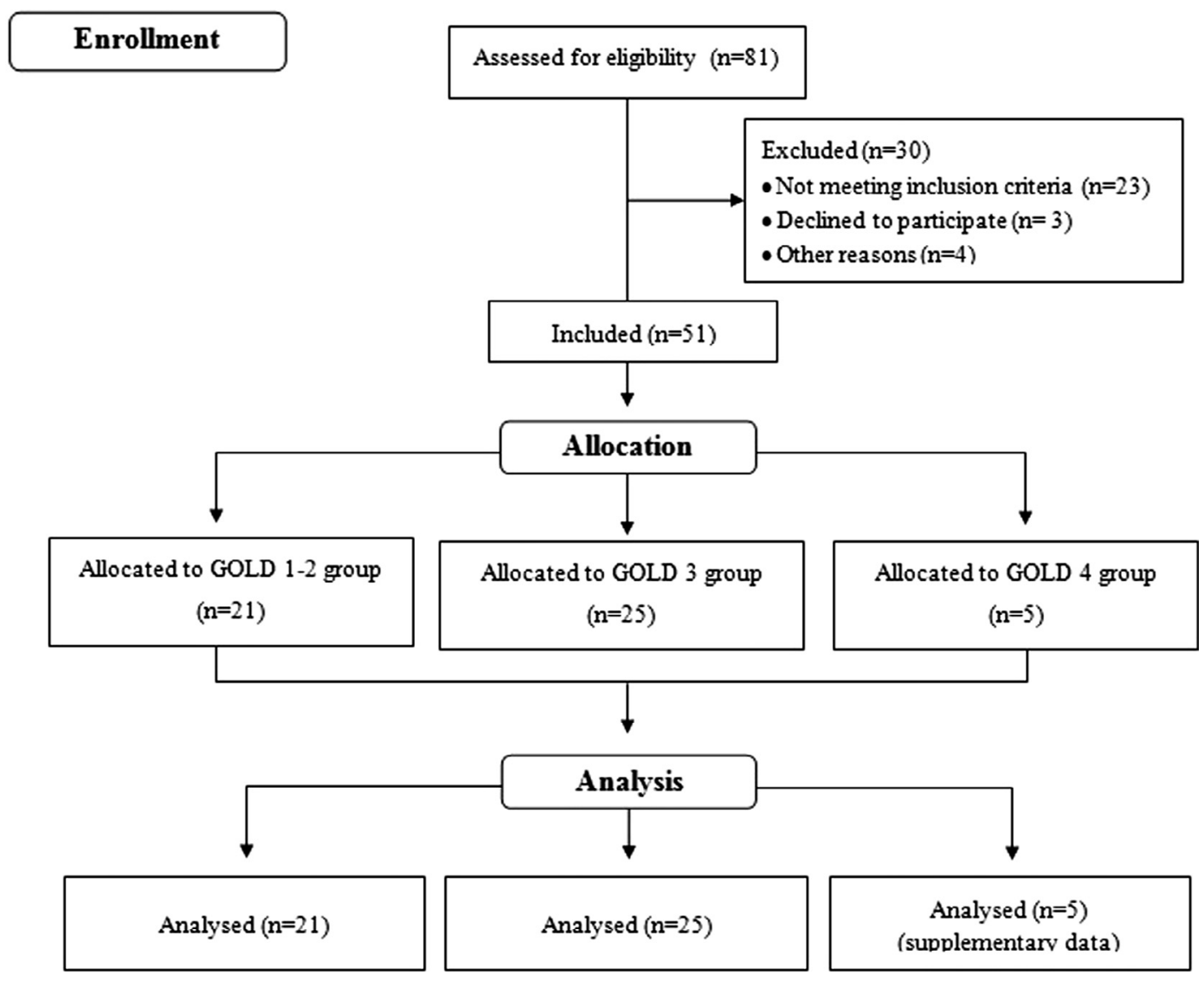

Fig. 1. Consort flow diagram.

\section{Results}

The study was composed of 51 patients with COPD (30 males and 21 females). Clinical and physiologic characteristics of the participants according to GOLD stages are presented in Table 1. Five patients were classified as GOLD stage 4, but due to the reduced number of participants, results were presented only in the Supplemental material (STable 1$)$. The sensitivity $(76.2 \%)$ and specificity $(70 \%)$ analysis were performed between IL-10 and lung function, with positive and negative predictive values, $64 \%$ and $80.8 \%$, respectively.

When performed the chi-square analysis, there were no association between GOLD groups and medicine intake $(p>.05)$. Anti-inflammatory drugs (GOLD 1-2: $\mathrm{n}=5$, GOLD $3: \mathrm{n}=1$ ) antihypertensive drugs (GOLD 1-2 $\mathrm{n}=13$; GOLD $3=18$ ); corticosteroid drugs (GOLD 1-2: $\mathrm{n}=12$, GOLD 3: $\mathrm{n}=16$ ); antidepressants drugs (GOLD 1-2: $\mathrm{n}=3$; GOLD 3: $\mathrm{n}=5$ ); anticholesterolemic drugs (GOLD 1-2: $\mathrm{n}=4$; GOLD 3: $\mathrm{n}=5$ ) and antidiabetic drugs (GOLD 1-2: $\mathrm{n}=4$, GOLD 3: $\mathrm{n}=1$ ).

Table 2 shows the relationship between inflammatory markers, pulmonary function, functional capacity, body composition and metabolic profile according to GOLD stages. We found significant correlation between IL-10 levels and predicted $\mathrm{FEV}_{1} \%(\mathrm{p}<.01)$, IL- 6 and total cholesterol $(\mathrm{p}=.018)$ and negative correlation between IL-10 levels and HDL-cholesterol $(\mathrm{p}<.01)$.

When considering COPD severity (GOLD stage groups) (Table 3), we found that patients in the GOLD 1-2 groups presented significant correlation between TNF- $\alpha$ and HDL cholesterol $(\mathrm{p}=.01)$ and IL-15 and $\mathrm{FEV}_{1} / \mathrm{FVC}(\mathrm{p}=.01)$, while GOLD 3 group showed significant correlation between IL-6 and IL-10 ( $\mathrm{p}<.01$ ), IL- 6 and total cholesterol $(p<.01)$ and negative correlation between IL-10 and HDL-cholesterol $(\mathrm{p}=.01)$.

\section{Discussion}

The main finding of this study showed that patients with lower lung function (GOLD 3 stage) presented lower levels of IL-10, triglycerides and visceral fat area, and higher IL- 6 and IL-6/IL-10 ratio when compared to patients with less severe COPD (GOLD 1-2 stages). We found no significant differences between the severity of COPD and TNF- $\alpha$, IL6 , IL-10/TNF- $\alpha$ ratio and IL-15, however, a positive correlation between lung function and inflammatory profile in patients classified as GOLD 1-2 was discovered.

When considering the whole sample, without divisions by COPD severity, we observed weak/moderate correlations between inflammatory and metabolic profile and lung function, especially between IL-10 and predicted $\mathrm{FEV}_{1} \%(\mathrm{r}=0.40)$. These results corroborate with the study conducted by Sun and colleagues, which showed that lower levels of IL-10 were associated with a higher frequency of bronchial asthma and COPD [29]. However, we choose to stratify the sample according to COPD severity to better understand the influence of inflammatory markers among these patients, since the outcomes may be different.

Systemic low-grade inflammation is considered a relevant characteristic of COPD, and it is considered a potential risk factor that can increase the occurrence of comorbidities [30]. Evidence suggests $[15,31]$ that systemic inflammation can occur with the first symptoms of the disease, even among patients who present "breathlessness during strenuous exertion" or "shortness of breath when hurrying". Additionally, studies have shown that systemic low-grade inflammatory condition is associated with deterioration of lung function [13]. The two most studied mediators of inflammation in this population are TNF$\alpha$ and IL- 6 , which feature pro-inflammatory conditions [11,32]. The positive correlation between IL- 6 and IL-10 in GOLD3 group can be, least in part, associated to counterbalance inflammatory status. In 
Table 1

Baseline characteristics of the participants according to GOLD stages.

\begin{tabular}{|c|c|c|c|c|}
\hline & Overall $(n=46)$ & GOLD 1-2 (n = 21) & GOLD $3(n=25)$ & $\mathrm{p}$-value \\
\hline \multicolumn{5}{|l|}{ Demographic characteristics } \\
\hline Age (years) & $67.98 \pm 10.03$ & $64.55 \pm 9.8$ & $70.72 \pm 9.54$ & .17 \\
\hline Sex (Male/Female) & $30 / 21$ & $14 / 7$ & $15 / 10$ & .64 \\
\hline \multicolumn{5}{|l|}{ Pulmonary function } \\
\hline $\mathrm{FEV}_{1} / \mathrm{FVC}(\%)$ & $55.92 \pm 12.79$ & $65.77 \pm 7.74$ & $47.63 \pm 10$ & $<.01^{*}$ \\
\hline $\mathrm{FEV}_{1} \%$ predicted & $47.94(40.36-63.92)$ & $66.17 \pm 9.44$ & $40.49 \pm 5.28$ & $<.01^{*}$ \\
\hline $6 \mathrm{MWT}$ (meters) & $479(422-546)$ & $542(422-583)$ & 467 (423.5-498.25) & .09 \\
\hline \multicolumn{5}{|c|}{ Inflammatory and metabolic markers } \\
\hline IL-6 (Log- pg/ml) & $0.30(0.02-0.51)$ & $0.13 \pm 0.37$ & $0.38 \pm 0.34$ & .04 \\
\hline TNF- $\alpha$ (Log- pg/ml) & $0.63(0.23-0.92)$ & $0.53(0.23-0.97)$ & $0.68(0.15-0.96)$ & .40 \\
\hline IL-10 (Log- pg/ml) & $0.26(0.11-0.36)$ & $0.35(0.28-0.45)$ & $0.20(0.05-0.32)$ & $<.01^{*}$ \\
\hline IL-15 (Log- pg/ml l) & $1.70(1.49-1.93)$ & $1.77(1.41-2.01)$ & $1.69(1.50-1.89)$ & .95 \\
\hline IL-6/IL-10 (Log- $\mathrm{pg} / \mathrm{ml})$ & $1.22(0.68-1.97)$ & $1.02(0.28-1.23)$ & $1.69(1.06-2.47)$ & $<.01^{*}$ \\
\hline IL-10/TNF- $\alpha$ (Log- pg/ml) & $0.50(0.19-1.02)$ & $0.78(0.23-1.70)$ & $0.32(0.16-0.98)$ & .10 \\
\hline Glucose (mg/dl) & $87.12(82.08-98.44)$ & 90.86 (82.39-101.83) & $85.40(80.84-94.75)$ & .21 \\
\hline Triglycerides (mg/dl) & $153.11(112.83-178.31)$ & $178.45 \pm 54.49$ & $140.94 \pm 36.18$ & $.03^{*}$ \\
\hline Total cholesterol (mg/dl) & $111.92 \pm 25.54$ & $119.11 \pm 25.56$ & $105.89 \pm 24.39$ & .08 \\
\hline HDL cholesterol (mg/dl) & $54.55(20.15-54.55)$ & $55.14(38.10-59.58)$ & $53.95(46.60-63.66)$ & .12 \\
\hline Albumin $(\mathrm{mg} / \mathrm{ml})$ & $65.10 \pm 22.34$ & $62.72 \pm 21.05$ & $66.86 \pm 23.56$ & .97 \\
\hline \multicolumn{5}{|l|}{ Body composition } \\
\hline BMI $\left(\mathrm{kg} / \mathrm{m}^{2}\right)$ & $26.08 \pm 15.60$ & $27.22(24.80-30.61)$ & $26.01(21.74-27.72)$ & .13 \\
\hline Fat mass $(\mathrm{kg})$ & $25.33 \pm 14.97$ & $26.40(21.20-32.50)$ & $23.2(15-29.30)$ & .09 \\
\hline Muscle mass (kg) & $24.42 \pm 6.32$ & $24.10(20.41-29.72)$ & $24.43(20.81-26.76)$ & .40 \\
\hline Visceral fat area $\left(\mathrm{cm}^{2}\right)$ & $111.81 \pm 51.58$ & $111.91(96.15-138.13)$ & $106.01(74.55-130.90)$ & $.04^{*}$ \\
\hline
\end{tabular}

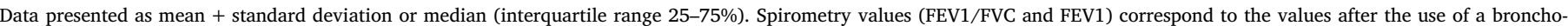
dilator.

* $\mathrm{p}<0.05$. FEV1: forced expiratory volume in one second; FVC: forced vital capacity; 6MWT: 6 min walk test; BMI: body mass index; IL-6: interleukin 6; TNF- $\alpha$ : tumor necrosis factoralfa; IL-15: interleukin 15; IL-10: interleukin 10.

consequence to pro-inflammatory response occur anti-inflammatory production cytokines, in the tentative restore inflammatory millie [33].

Although studies have indicated high levels of IL- 6 in the peripheral blood of patients with COPD when compared to healthy individuals [11], a meta-analysis [34] showed that elevated levels of IL-6 might not be associated with the severity of the disease, however our finding showed statistical differences in IL- 6 between groups according to the severity of the disease. In TNF- $\alpha$ concentrations no significance difference was observed. This association is inconsistent with the scientific literature, with some studies reporting an association between TNF- $\alpha$ and pulmonary obstruction [11,22,35], while others disagree [36-38].

It has been reported that IL-10, an important anti-inflammatory cytokine, is expressed in response to the presence of excessive regulation of pro-inflammatory cytokines, with the purpose of suppressing macrophage activity and inhibiting the production of interferon gamma, TNF- $\alpha$, IL- 2, IL-12 and IL-18 [22]. One potential mechanism that may explain regulatory functions by IL-10 is the binding to a specific cell surface receptor (IL-10R) inhibiting nuclear translocation of the NF-kb and its DNA-binding activity, blocking pro-inflammatory cytokines, specially, TNF- $\alpha$, IL- 6 and others [39].

The present study showed lower concentration of IL-10 in GOLD 3 group when compared to GOLD 1-2 groups. We believe that the accentuated inflammatory status, at least in part, is due to lower levels of IL-10, which support inflammatory profile and exacerbate inflammatory response, leading to a more severe level of COPD. Similar response was also observed in the study conducted by Huang et al. [22],

Table 2

Correlations between inflammatory markers and other variables in all patients.

\begin{tabular}{|c|c|c|c|c|}
\hline & IL-6 & TNF- $\alpha$ & IL-10 & IL-15 \\
\hline & r (IC 95\%) & r (IC 95\%) & r (IC 95\%) & r (IC 95\%) \\
\hline $\mathrm{FEV}_{1} / \mathrm{FVC}(\%)$ & $-0.26(-0.50 ; 0.07)$ & $-0.05(-0.24 ; 0.39)$ & $0.22(-0.06 ; 0.50)$ & $0.08(-0.19 ; 0.41)$ \\
\hline $\mathrm{FEV}_{1} \%$ predict & $-0.26(-0.42 ; 0.15)$ & $-0.08(-0.22 ; 0.36)$ & $0.35(0.12 ; 0.59)$ & $0.01(-0.28 ; 0.33)$ \\
\hline $6 \mathrm{MWT}(\mathrm{m})$ & $-0.04(-0.38 ; 0.24)$ & $0.14(-0.23 ; 0.42)$ & $0.08(-0.28 ; 0.33)$ & $-0.14(-0.34 ; 0.23)$ \\
\hline $\mathrm{BMI}\left(\mathrm{kg} / \mathrm{m}^{2}\right)$ & $0.03(-0.29 ; 0.36)$ & $0.04(-0.23 ; 0.39)$ & $0.04(-0.21 ; 0.39)$ & $0.12(-0.16 ; 0.46)$ \\
\hline Fat mass (kg) & $-0.04(-0.31 ; 0.27)$ & $0.05(-0.24 ; 0.36)$ & $-0.09(-0.33 ; 0.30)$ & $0.12(-0.21 ; 0.39)$ \\
\hline Muscle mass (kg) & $0.19(-0.18 ; 0.45)$ & $0.12(-0.21 ; 0.43)$ & $0.16(-0.03 ; 0.52)$ & $-0.05(-0.32 ; 0.26)$ \\
\hline Visceral fat area $\left(\mathrm{cm}^{2}\right)$ & $-0.23(-0.45 ; 0.24)$ & $0.05(-0.08 ; 0.29)$ & $0.04(-0.19 ; 0.32)$ & $0.07(-0.30 ; 0.34)$ \\
\hline $\mathrm{IL}-6(\mathrm{pg} / \mathrm{ml})$ & - & $0.03(-0.32 ; 0.27)$ & $0.21(-0.12 ; 0.53)$ & $0.20(-0.14 ; 0.46)$ \\
\hline TNF- $\alpha(\mathrm{pg} / \mathrm{ml})$ & $0.03(-0.32 ; 0.27)$ & - & $-0.12(-0.17 ; 0.49)$ & $0.18(-0.06 ; 0.55)$ \\
\hline IL-10 (pg/ml) & $0.21(-0.12 ; 0.53)$ & $-0.12(-0.17 ; 0.49)$ & - & $0.12(-0.06 ; 0.58)$ \\
\hline IL-15 (pg/ml) & $0.20(-0.14 ; 0.46)$ & $0.18(-0.06 ; 0.55)$ & $0.12(-0.06 ; 0.58)$ & - \\
\hline Glucose $(\mathrm{mg} / \mathrm{dl})$ & $0.10(-0.25 ; 0.26)$ & $-0.10(-0.42 ; 0.23)$ & $0.28(-0.07 ; 0.56)$ & $0,08(-0.24 ; 0.30)$ \\
\hline Triglycerides (mg/dl) & $-0.12(-0.39 ; 0.21)$ & $-0.01(-0.32 ; 0.33)$ & $0.21(0.02 ; 0.40)$ & $0.07(-0.24 ; 0.39)$ \\
\hline Total cholesterol (mg/dl) & $0.34(-0.05 ; 0.66)^{*}$ & $-0.16(-0.42 ; 0.23)$ & $0.06(-0.16 ; 0.48)$ & $0.04(-0.17 ; 0.44)$ \\
\hline HDL cholesterol (mg/dl) & $-0.13(-0.34 ; 0.13)$ & $-0.04(-0.36 ; 0.28)$ & $-0.49(-0.74 ;-0.19)^{1}$ & $-0.14(-0.40 ; 0.01)$ \\
\hline
\end{tabular}

$* \mathrm{p}<.05$.

${ }^{1} \mathrm{p}<.01$; 6MWT: 6-min walk test; BMI: body mass index; IL-6: interleukin 6; TNF- $\alpha$ : tumor necrosis factor-alfa; IL-15: interleukin 15; IL-10: interleukin 10; IC 95\%: confidence interval of $95 \%$. 
Table 3

Correlations between inflammatory markers and other variables according to GOLD stages.

\begin{tabular}{|c|c|c|c|c|c|c|c|c|}
\hline & \multicolumn{2}{|l|}{ IL-6 } & \multicolumn{2}{|l|}{ TNF- $\alpha$} & \multicolumn{2}{|l|}{ IL-10 } & \multicolumn{2}{|l|}{ IL-15 } \\
\hline & GOLD 1-2 & GOLD 3 & GOLD 1-2 & GOLD 3 & GOLD 1-2 & GOLD 3 & GOLD 1-2 & GOLD 3 \\
\hline $\mathrm{FEV}_{1} / \mathrm{FVC}(\%)$ & -0.17 & -0.14 & -0.07 & -0.02 & -0.31 & -0.09 & $0.56^{*}$ & -0.18 \\
\hline $\mathrm{FEV}_{1} \%$ predict & -0.01 & -0.04 & 0.12 & -0.08 & -0.33 & -0.07 & 0.29 & -0.16 \\
\hline $6 \mathrm{MWT}(\mathrm{m})$ & -0.17 & 0.19 & 0.27 & 0.09 & 0.16 & -0.19 & -0.07 & -0.32 \\
\hline $\mathrm{BMI}\left(\mathrm{kg} / \mathrm{m}^{2}\right)$ & 0.04 & 0.16 & 0.03 & 0.05 & -0.05 & -0.13 & 0.16 & 0.06 \\
\hline Fat mass $(\mathrm{kg})$ & -0.05 & 0.12 & 0.01 & 0.06 & -0.16 & -0.23 & 0.32 & -0.05 \\
\hline Muscle mass (kg) & -0.03 & 0.38 & 0.02 & 0.28 & 0.04 & 0.28 & -0.24 & 0.15 \\
\hline Visceral fat area $\left(\mathrm{cm}^{2}\right)$ & -0.24 & 0.13 & -0.02 & 0.08 & -0.20 & -0.29 & 0.28 & -0.07 \\
\hline IL-6 (pg/ml) & - & - & 0.15 & -0.21 & -0.11 & $0.55^{1}$ & 0.01 & 0.36 \\
\hline TNF- $\alpha(\mathrm{pg} / \mathrm{ml})$ & 0.15 & -0.21 & - & - & 0.23 & -0.23 & 0.13 & 0.11 \\
\hline $\mathrm{IL}-10(\mathrm{pg} / \mathrm{ml})$ & -0.11 & $0.55^{\Psi}$ & 0.23 & -0.23 & - & - & -0.06 & 0.38 \\
\hline IL-15 (pg/ml) & 0.01 & 0.36 & 0.13 & 0.11 & -0.06 & 0.38 & - & - \\
\hline Glucose (mg/dl) & 0.15 & 0.26 & -0.15 & 0.00 & -0.02 & 0.46 & -0.15 & 0.31 \\
\hline Triglycerides (mg/dl) & -0.11 & -0.15 & -0.18 & 0.20 & -0.08 & 0.23 & 0.01 & 0.07 \\
\hline Total cholesterol (mg/dl) & 0.34 & $0.52^{\Psi}$ & -0.25 & -0.22 & -0.12 & 0.11 & -0.06 & 0.16 \\
\hline HDL cholesterol (mg/dl) & -0.10 & -0.28 & $-0.58^{*}$ & 0.31 & -0.35 & $-0.50^{*}$ & 0.05 & -0.37 \\
\hline
\end{tabular}

$* \mathrm{p}<.05$.

${ }^{1} \mathrm{p}<.01 .6 \mathrm{MWT}$ : 6 min walk test. BMI: body mass index; IL-6: interleukin 6; TNF- $\alpha$ : tumor necrosis factor-alfa; IL-15: interleukin 15; IL-10: interleukin 10.

that reported a positive correlation between IL-10 levels and lung function variables. In addition, when we performed the sensitivity and specificity analysis between IL-10 and lung function, IL-10 presented a good variable to identify the positive (64\%) and negative predictive values $(80.8 \%)$

The reduction of IL-10 concentrations among patients with lower lung function supports inflammatory processes. Additionally, it is known that systemic low-grade inflammation increases lipolysis of the adipose tissue, which increases the activity of lipolytic enzymes, such as adipose triglyceride lipase (ATGL) and hormone sensitivity lipase (HSL), providing the release of free fatty acids (FFAs). Thus, the FFAs (mainly triglycerides) released into the bloodstream accumulate mainly in muscles and the liver, which could trigger hepatic steatosis [40]. This process can justify the reduction of triglycerides and visceral fat area in the GOLD 3 group. Recently, IL-6/IL-10 ratio has been used as a good marker for degree inflammatory status with several diseases and conditions, such as AIDS, polytrauma, drugs abuse [41-43]. Thus, IL-6/IL10 ratio could be an interesting strategy to prevent severity disease earlier. In the present study, we have showed that IL-6/IL-10 ratio was higher for GOLD 3 compared to GOLD 1-2, beside there was lower IL10 concentration for GOLD 3. However, more studies are needed to better understand the mechanisms involved in this process.

Regarding IL-15, it plays an important role in the antiviral immune response, contributing to the activation of survival cells and natural killer (NK) cells, CD8 +, and NK T. Additionally, the hypertrophy of muscle fibers also favors and antagonizes muscle protein wasting, which can exert important influence in COPD, specially because patients with the disease usually have musculoskeletal dysfunction $[44,45]$. Studies investigating the role of IL-15 are limited among patients with COPD, but it is important to elucidate complications often exacerbated in some patients [46]. Our study only involved stable patients with COPD, and we found no difference between the severity of the disease and IL-15. However, a moderate positive correlation between IL-15 and $\mathrm{FEV}_{1} / \mathrm{FVC}$ (\%) was observed in the GOLD 1-2 groups. Thus, we can speculate that this association may be linked to the effect of IL-15 increasing mitochondrial activity, membrane potential and decreasing lipid deposition, which may have influenced a better functional capacity and performance of lung function when compared to GOLD 4 group (S-Table 1, data not showed) [47].

\subsection{Study Strengths and limitations}

The ECLIPSE study showed a large number of obese patients with COPD and the presence of inflammatory profile [48], which could be considering a confounding factor. Regarding that, the main strength of our study was the sample being composed of only eutrophic patients.

However, our study has a few limitations. The absence of a control group, not assessing comorbidities and the lack of intracellular analysis of inflammation, which could give a complete perception of the inflammatory profile of the patients, should be taken into account when interpreting our results. Also, future studies could be conducted to evaluate the relationship between sputum analysis and anti-inflammatory cytokines.

\subsection{Clinical implications}

The decrease of anti-inflammatory biomarkers among patients with lower lung function compared to mild COPD may indicate an increased risk of development of other comorbidities, such as hepatic steatosis and insulin resistance. IL-10 may also have a therapeutic role among patients with COPD, since it inhibits proinflammatory chemokines and proteinases, which may be involved in the destruction of elastin in the lung parenchyma, which influence the prognosis of the disease.

Thus, our findings provide important information regarding proinflammatory factors, supporting a new view of the role of the antiinflammatory cytokines in the severity of COPD and giving another perspective on the changes that may be caused by its decrease.

\section{Conclusion}

In conclusion, we suggest that patients with severe COPD can exhibit compromised "inflammatory status", characterized by higher IL-6, IL-6/IL-10 ratio and lower IL-10 concentration. Furthermore, IL-10 seems to be an interesting cytokine to be investigated in this kind of patients.

\section{Author contributions}

B.S.A.S. was the primary investigator and had full access to all the data in the study and takes responsibility for the integrity of the data and the accuracy of the data analysis. F.S.L., D.R., J.S.U., F.E.R., A.P.C.F.F., R.N.S., I.B.T., L.A.G., E.M.C.R. were involved in data generation analysis and interpretation of the data and in preparation or critical revision of the manuscript. All authors contributed to the writing and revising of the manuscript, and read and approved the final manuscript. 


\section{Funding}

This study was supported by National Council of Scientific Researches (Cnpq) (Grant No. 470742/2014-3).

\section{Role of sponsors}

The funders had no role in study design, data collection and analysis, decision to publish, or preparation of the manuscript.

\section{Appendix A. Supplementary material}

Supplementary data associated with this article can be found, in the online version, at http://dx.doi.org/10.1016/j.cyto.2017.10.018.

\section{References}

[1] GOLD, Global strategy for the diagnosis, management and prevention of COPD 2016. Available from: <http://goldcopd.org/> .

[2] A. Khakban, D.D. Sin, J.M. FitzGerald, R. Ng, Z. Zafari, B. McManus, et al., Ten-year trends in direct costs of COPD: a population-based study, Chest 148 (3) (2015) 640-646.

[3] D.M. Mannino, K. Higuchi, T.C. Yu, H. Zhou, Y. Li, H. Tian, et al., Economic burden of COPD in the presence of comorbidities, Chest 148 (1) (2015) 138-150.

[4] L.E. Vanfleteren, M.A. Spruit, M. Groenen, S. Gaffron, V.P. van Empel, P.L. Bruijnzeel, et al., Clusters of comorbidities based on validated objective measurements and systemic inflammation in patients with chronic obstructive pulmonary disease, Am. J. Resp. Criti. Care Med. 187 (7) (2013) 728-735.

[5] L.M. Steuten, E.C. Creutzberg, H.J. Vrijhoef, E.F. Wouters, COPD as a multicomponent disease: inventory of dyspnoea, underweight, obesity and fat free mass depletion in primary care, Primary Care Resp. J.: J. Gen. Pract. Airways Group 15 (2) (2006) 84-91.

[6] E. Barreiro, The role of MicroRNAs in COPD muscle dysfunction and mass loss: implications on the clinic, Exp Rev. Resp. Med. 10 (9) (2016) 1011-1022.

[7] C.E. Bolton, J.K. Quint, M.T. Dransfield, Cardiovascular disease in COPD: time to quash a silent killer, The Lancet Resp. Med. 4 (9) (2016) 687-689.

[8] D.L. Matte, M.M. Pizzichini, A.T. Hoepers, A.P. Diaz, M. Karloh, M. Dias, et al., Prevalence of depression in COPD: a systematic review and meta-analysis of con trolled studies, Resp. Med. 117 (2016) 154-161.

[9] R. Okazaki, COPD and bone, Clinical calcium. 26 (8) (2016) 1195-1200.

[10] E. Barreiro, J. Gea, Respiratory and limb muscle dysfunction in COPD, COPD. 12 (4) (2015) 413-426.

[11] F. Garcia-Rio, M. Miravitlles, J.B. Soriano, L. Munoz, E. Duran-Tauleria, G. Sanchez, et al., Systemic inflammation in chronic obstructive pulmonary disease: a population-based study, Resp. Res. 11 (2010) 63.

[12] W.Q. Gan, S.F. Man, A. Senthilselvan, D.D. Sin, Association between chronic obstructive pulmonary disease and systemic inflammation: a systematic review and a meta-analysis, Thorax 59 (7) (2004) 574-580.

[13] B. Su, T. Liu, H. Fan, F. Chen, H. Ding, Z. Wu, et al., Inflammatory markers and the risk of chronic obstructive pulmonary disease: a systematic review and meta-analysis, PloS one 11 (4) (2016) e0150586.

[14] M. Poulain, M. Doucet, V. Drapeau, G. Fournier, A. Tremblay, P. Poirier, et al, Metabolic and inflammatory profile in obese patients with chronic obstructive pulmonary disease, Chronic Resp. Dis. 5 (1) (2008) 35-41.

[15] R. Garrod, J. Marshall, E. Barley, S. Fredericks, G. Hagan, The relationship between inflammatory markers and disability in chronic obstructive pulmonary disease (COPD), Primary Care Resp. J: J. General Pract. Airways Group 16 (4) (2007) 236-240.

[16] A. Papi, M.S. Magnoni, C.C. Muzzio, G. Benso, A. Rizzi, Phenomenology of COPD: interpreting phenotypes with the ECLIPSE study. Monaldi archives for chest disease $=$, Archivio Monaldi per le Malattie del Torace 83 (1-2) (2016) 721.

[17] M. Castellucci, M. Rossato F. Calzetti, N. Tamassia, S. Zeminian, M.A. Cassatella, et al., IL-10 disrupts the Brd4-docking sites to inhibit LPS-induced CXCL8 and TNFalpha expression in monocytes: Implications for chronic obstructive pulmonary disease, J. Allergy Clin. Immunol. 136(3) (2015) 781-991.e9.

[18] Z. Liu, W. Fan, J. Chen, Z. Liang, L. Guan, The role of Interleukin 15 in protein degradation in skeletal muscles in rats of chronic obstructive pulmonary disease, Int. J Clin. Exp. Med. 8 (2) (2015) 1976-1984.

[19] D.A. Cockayne, D.T. Cheng, B. Waschki, S. Sridhar, P. Ravindran, H. Hilton, et al., Systemic biomarkers of neutrophilic inflammation, tissue injury and repair in COPD patients with differing levels of disease severity, PloS one 7 (6) (2012) e38629.

[20] B. Eriksson, H. Backman, A. Bossios, A. Bjerg, L. Hedman, A. Lindberg, et al.. Only severe COPD is associated with being underweight: results from a population survey, ERJ Open Res. 2(3) (2016).

[21] A.A. Lambert, N. Putcha, M.B. Drummond, A.M. Boriek, N.A. Hanania, V. Kim, et al., Obesity is associated with increased morbidity in moderate to severe COPD, Chest (2016).

[22] A.X. Huang, L.W. Lu, W.J. Liu, M. Huang, Plasma inflammatory cytokine IL-4, IL-8, IL-10, and TNF-alpha levels correlate with pulmonary function in patients with asthma-chronic obstructive pulmonary disease (COPD) overlap syndrome, Med. Sci.
Monitor: Int. Med. J. Exp. Clin. Res. 22 (2016) 2800-2808.

[23] H.A. Miot, Tamanho da amostra em estudos clínicos e experimentais, J. Vascular Brasileiro. 10 (2011) 275-278.

[24] A.C.P. Carlos, J.M. Jansen, S.S.M. Barreto, J. Marinho, N. Sulmonett, R.M. Dias, et al., Diretrizes para testes de função pulmonar, J. Brasileiro de Pneumologia. 3 (28) (2002) 2-237.

[25] M.R. Miller, J. Hankinson, V. Brusasco, F. Burgos, R. Casaburi, A. Coates, et al, Standardisation of spirometry, Eur. Resp. J. 26 (2) (2005) 319-338.

[26] J.A. Neder, S. Andreoni, A. Castelo-Filho, L.E. Nery, Reference values for lung function tests. I. Static volumes. Braz. J. Med. Biol Res. = Revista brasileira de pesquisas medicas e biologicas/Sociedade Brasileira de Biofisica [et al.] 32(6) (1999) 703-717.

[27] A.E. Holland, M.A. Spruit, T. Troosters, M.A. Puhan, V. Pepin, D. Saey, et al., An official European Respiratory Society/American Thoracic Society technical standard: field walking tests in chronic respiratory disease, Eur. Resp. J. 44 (6) (2014) 1428-1446.

[28] M.M. Bradford, A rapid and sensitive method for the quantitation of microgram quantities of protein utilizing the principle of protein-dye binding, Anal. Biochem. 72 (1976) 248-254

[29] L. Sun, T.T. Cornell, A. LeVine, A.A. Berlin, V. Hinkovska-Galcheva, A.J. Fleszar et al., Dual role of interleukin-10 in the regulation of respiratory syncitial virus (RSV)-induced lung inflammation, Clin. Exp. Immunol. 172 (2) (2013) 263-279.

[30] R. Broekhuizen, E.F. Wouters, E.C. Creutzberg, A.M. Schols, Raised CRP levels mark metabolic and functional impairment in advanced COPD, Thorax 61 (1) (2006) $17-22$.

[31] J.C. Hogg, F. Chu, S. Utokaparch, R. Woods, W.M. Elliott, L. Buzatu, et al., The nature of small-airway obstruction in chronic obstructive pulmonary disease, New Engl. J. Med. 350 (26) (2004) 2645-2653.

[32] S.E. Tanni, N.R.G. Pelegrino, A.Y.O. Angeleli, C. Correa, I. Godoy, Smoking status and tumor necrosis factor-alpha mediated systemic inflammation in COPD patients, J. Inflamm. 7 (1) (2010) 1-7.

[33] K. Zobel, P. Martus, M.W. Pletz, S. Ewig, M. Prediger, T. Welte, et al., Interleukin 6 , lipopolysaccharide-binding protein and interleukin 10 in the prediction of risk and etiologic patterns in patients with community-acquired pneumonia: results from the German competence network CAPNETZ, BMC Pulm. Med. 12 (2012) 6.

[34] J. Wei, X.F. Xiong, Y.H. Lin, B.X. Zheng, D.Y. Cheng, Association between serum interleukin-6 concentrations and chronic obstructive pulmonary disease: a systematic review and meta-analysis, PeerJ. 3 (2015) e1199.

[35] J. Xie, X-y. Yang, J-d Shi ,X-q Deng, W. Long, A new inflammation marker of chronic obstructive pulmonary disease-adiponectin, World J. Emerg. Med. 1(3) (2010) 190-195.

[36] S. Yende, G.W. Waterer, E.A. Tolley, A.B. Newman, D.C. Bauer, D.R. Taaffe, et al, Inflammatory markers are associated with ventilatory limitation and muscle dysfunction in obstructive lung disease in well functioning elderly subjects, Thorax 61 (1) (2006) 10-16

[37] K.-C. Shin, J.H. Chung, K.H. Lee, Effects of TNF- $\alpha$ and Leptin on weight loss in patients with stable chronic obstructive pulmonary disease, Kor. J. Int. Med. 22 (4) (2007) 249-255.

[38] K. Piehl-Aulin, I. Jones, B. Lindvall, A. Magnuson, S.M. Abdel-Halim, Increased serum inflammatory markers in the absence of clinical and skeletal muscle inflammation in patients with chronic obstructive pulmonary disease, Resp.; Int. Rev. Thoracic Dis. 78 (2) (2009) 191-196.

[39] A. Saxena, S. Khosraviani, S. Noel, D. Mohan, T. Donner, A.R. Hamad, Interleukin10 paradox: a potent immunoregulatory cytokine that has been difficult to harness for immunotherapy, Cytokine 74 (1) (2015) 27-34.

[40] A.A. Teixeira, F.S. Lira, G.D. Pimentel, C. Oliveira de Souza, H. Batatinha, L.A. Biondo, et al., Aerobic exercise modulates the free fatty acids and inflammatory response during obesity and cancer cachexia, Critic. Rev. Eukaryotic Gene Express. 26 (3) (2016) 187-198.

[41] J. Sun, J. Su, Y. Xie, M.T. Yin, Y. Huang, L. Xu, et al., Plasma IL-6/IL-10 Ratio and IL-8 LDH, and HBDH level predict the severity and the risk of death in AIDS patients with pneumocystis pneumonia, 201620161583951.

[42] H.B. Sapan, I. Paturusi, I. Jusuf, I. Patellongi, M.N. Massi, A.D. Pusponegoro, et al., Pattern of cytokine (IL-6 and IL-10) level as inflammation and anti-inflammation mediator of multiple organ dysfunction syndrome (MODS) in polytrauma, Int. J. Burns Trauma. 6 (2) (2016) 37-43.

[43] F.P. Moreira, J.R. Medeiros, A.C. Lhullier, L.D. Souza, K. Jansen, L.V. Portela, et al., Cocaine abuse and effects in the serum levels of cytokines IL- 6 and IL-10, Drug Alcohol Depend. 158 (2016) 181-185.

[44] M.T. Zdrenghea, P. Mallia, S.L. Johnston, Immunological pathways in virus-induced COPD exacerbations: a role for IL-15, Eur. J. Clin. Invest. 42 (9) (2012) 1010-1015.

[45] L.S. Quinn, K.L. Haugk, K.H. Grabstein, Interleukin-15: a novel anabolic cytokine for skeletal muscle, Endocrinology 136 (8) (1995) 3669-3672.

[46] C.M. Freeman, C.H. Martinez, J.C. Todt, F.J. Martinez, M.K. Han, D.L. Thompson, et al., Acute exacerbations of chronic obstructive pulmonary disease are associated with decreased CD4 + \& CD8 + T cells and increased growth \& differentiation factor-15 (GDF-15) in peripheral blood, Resp. Res. 16 (1) (2015) 94.

[47] N.G. Barra, R. Palanivel, E. Denou, M.V. Chew, A. Gillgrass, T.D. Walker, et al., Interleukin-15 modulates adipose tissue by altering mitochondrial mass and activity, PloS one 9 (12) (2014) e114799.

[48] P. Joppa, R. Tkacova, F.M. Franssen, C. Hanson, S.I. Rennard, E.K. Silverman, et al., Sarcopenic Obesity, Functional Outcomes, and Systemic Inflammation in Patients With Chronic Obstructive Pulmonary Disease, J. Am. Med. Direct. Assoc. 17 (8) (2016) 712-718. 